\title{
Investigación como estrategia pedagógica para el fomento de la identidad cultural en el municipio de Tasajera ${ }^{1}$
}

\section{Research as a pedagogical strategy in the promotion of cultural identity in the municipality of Tasajera}

DOI: http://dx.doi.org/10.17981/cultedusoc.9.3.2018.41

Artículo de investigación. Fecha de recepción: 15/06/2018. Fecha de aceptación: 27/11/2018

Alicia Fernández Cantillo;

Sugey Fernández Cantillo y Sara Fernández Cantillo ${ }^{3}$

Institución Educativa Distrital (IED) Rural de Tasajera sede Santiago Montaño (Colombia)

alicfe@hotmail.com

Para citar este artículo:

Fernández, A., Fernández, S. y Fernández, S.(2018). Investigación como estrategia pedagógica para el fomento de la identidad cultural en el municipio de Tasajera. Cultura. Educación y Sociedad 9(3), 363-370. DOI: http://dx.doi.org/10.17981/cultedusoc.9.3.2018.41

\section{Resumen}

Este trabajo presenta los resultados derivados de la utilización de la Investigación como Estrategia Pedagógica, empleada como una metodología que favorece el desarrollo del proceso enseñanza-aprendizaje y permite generar nuevos conocimientos a partir de la realidad educativa. En la construcción de este proyecto la intención es fundamentar el uso de la investigación como estrategia para afianzar en los estudiantes la identidad cultural propia de su municipio. La población estuvo conformada por los estudiantes de la Institución Educativa Distrital (IED) Rural de Tasajera sede Santiago Montaño. A partir de las entrevistas realizadas a personas de tercera edad, los niños de la IED Santiago Montaño, realizaron un libro de historias de vida de la población de Tasajera en la cual se recopiló información relacionada con la tradición y cultura de este municipio.

Palabras clave: Investigación como estrategia pedagógica, identidad cultural, método biográfico.

\section{Abstract}

This article presents the results derived from the Research as Pedagogic Strategy (IEP) becomes a methodology that favors the development of the teaching-learning process, having as intentionality to generate new knowledge from the educational reality. This is why it is a fundamental pillar in the construction of this project, which seeks to use research as a strategy to strengthen students' cultural identity. Promote cultural identity in the municipality of Tasajera using Research as a Pedagogical Strategy (IEP). The population was conformed by the students of the District Educational Institution (IED) Rural of Tasajera seat Santiago Montaño. From the interviews carried out with elderly people, the children of the IED Santiago Montaño, made a book of life stories of the population of Tasajera in which information related to the tradition and culture of this municipality was collected.

Keywords: Research as pedagogical strategy, cultural identity, biographical method

1 Este artículo ha sido derivado del Proyecto Fortalecimiento de la Cultura Ciudadana y Democrática en CT+I a través de la IEP apoyada en TIC en el Dpto. del Magdalena.

2 Líder del grupo de investigación "Rescatadores de Historia".

3 Docentes de la institución Educativa Distrital (IED) Rural de Tasajera sede Santiago Montaño.

- The author; licensee Universidad de la Costa - CUC.

Cultura, Educación y Sociedad vol. 9 no. 3, pp. 363-370. Diciembre, 2018

Barranquilla. ISSN 2389-7724 Online 


\section{Introducción}

En la Institución Educativa Departamental Rural de Tasajera se evidencia desconocimiento sobre la identidad cultural y se observa una pobre valoración de sus raíces ancestrales, esto genera que los educandos no se cuestionen, ni se interesen por desarrollar iniciativas para estudiar el origen de su municipio y su cultura; de acuerdo a Samper, J. \& Maussa, E. (2014) la socialización de la cultura debe realizarse mediante el proceso de escolarización. Se hace necesario implementar estrategias que fomenten el interés por conocer su cultura y fortalezcan su identidad cultural (Rodríguez, 2015).

El proyecto de rescatar y fortalecer la identidad cultural de los estudiantes del corregimiento de Tasajera, se hace necesario porque a partir de su propia historia, podrán reconocer sus falencias, respetar y la valorar su cultura. La investigación sobre lo referente a sus orígenes, costumbres, tradición, valores, y en general todo lo que enmarca la historia de un pueblo, hace que se conviertan en jóvenes indagadores y con sentido de pertenencia, capaces de incursionar en los procesos de cambio de su comunidad. En este sentido, resulta imperativo fortalecer procesos de participación ciudadana que coadyuven a la consolidación de sus identidades. De la Concepción (2015) destaca la necesidad de que, en el contexto educativo, se propicien los mecanismos de participación como vía para desarrollar ciudadanía.

En este sentido, considerando el proceso investigativo como una metodología asertiva para el trabajo en el aula, se puede decir que esta investigación dentro de la institución educativa no es de un campo, un área o una disciplina específica, sino que pretende descubrir y generar conocimiento útil y relacionado con diversas áreas del contenido del currículo, independiente del área donde surja la idea. En suma, esta es una metodología que favorece el desarrollo de la enseñanza y aprendizaje, teniendo como intencionalidad generar nuevos conocimientos a partir de la realidad educativa (Mejía y Grisales, s.f.; Mejía y Manjarrés, 2011; Orozco, 2015; Villalba, 2012).

Con base a lo anterior, surge este proyecto, el cual para su creación se tuvieron en cuenta los siguientes aspectos; Se partió inicialmente de una necesidad que atañe a la Institución Educativa Departamental Rural de Tasajera, donde es notorio la falta de conocimiento de los orígenes de este corregimiento por parte de los estudiantes, esto generó la iniciativa por parte de los docentes investigadores a trabajar en este aspecto tan importante para los habitantes del lugar.

El fomento de la identidad cultural conlleva una serie de significados sumamente importantes, Geertz (2006), señala que la cultura se expresa en un sistema de concepciones simbólicas, por medio de las cuales la gente se comunica y desarrolla conocimientos que se perpetúan en actitudes a lo largo de la vida. La cultura es susceptible a ir cambiando y su función es dotar de sentido al mundo y hacerlo comprensible. El entramado de relaciones que está detrás del término cultura es muy complejo, se presenta como una "telaraña de significados" que nosotros mismos hemos tejido a nuestro alrededor y dentro de la cual quedamos inevitable e inconscientemente atrapados. 
"Las identidades se construyen precisamente a partir de la apropiación, por parte de los actores sociales de determinados repertorios culturales considerados simultáneamente como diferenciadores y definidores de la propia unidad y especificidad. Los conceptos de cultura e identidad están estrechamente interrelacionados. En efecto, "nuestra identidad" sólo puede consistir en la apropiación distintiva de ciertos repertorios culturales que se encuentran en nuestro entorno social, en nuestro grupo o en nuestra sociedad" (Plan Maestro de las Culturas, p. 33).

El hablar de identidad implica marcar fronteras entre un 'nosotros' y los 'otros', y son precisamente los rasgos culturales distintivos, los que nos permiten diferenciarnos de los demás y desarrollar sentido de pertenencia con la realidad que nos rodea.

En este sentido representa el conjunto de los rasgos compartidos o no dentro de un grupo. De aquí su papel de operadora de diferenciación (Giménez, 2012). Ahora podemos entender en palabras de Giménez, por qué los conceptos de cultura y de identidad constituyen una pareja indisociable, y también, podemos entender que la concepción que se tenga de la cultura va a comandar la concepción correspondiente de la identidad. Si soy, por ejemplo, "posmoderno" y concibo la cultura como esencialmente fragmentada, híbrida, descentrada y fluida, mi concepción de la identidad también revestirá los mismos caracteres.

La definición de identidad cultural es inherente a un grupo social con el cual se comparten rasgos culturales, costumbres, valores y creencias. La identidad es un concepto variable, se recrea individual y colectivamente, $\mathrm{y}$ se alimenta de forma continua de la influencia de variables exteriores. De acuerdo con estudios antropológicos y sociológicos, la identidad surge de la pertenencia, por diferenciación y como reafirmación frente al otro grupo o persona (Molano, 2007; Morante, 2012).

Teniendo en cuenta a los referentes teóricos mencionados, este proyecto dirige su atención a fomentar el aspecto de la identidad cultural de los estudiantes de Tasajera, buscando que éstos afiancen este tema tan relevante que puede llegar a generar transformación social en la comunidad.

\section{Metodología}

El artículo que se presenta es un producto derivado del estudio titulado la Investigación como estrategia pedagógica para el fomento de la identidad cultural en el municipio de Tasajera. Desarrollado en la institución Educativa Distrital (IED) Rural de Tasajera sede Santiago Montaño; su objetivo principal ha sido fomentar la identidad cultural en el municipio de tasajera, utilizando la investigación como estrategia pedagógica; el estudio contempla una metodología con el siguiente orden:

En su diseño se utilizó el modelo de la investigación cualitativa, el cual consiste en "una categoría de diseños de investigación que extraen descripciones a partir de observaciones que adoptan la forma de entrevistas, narraciones, notas de campo, grabaciones, transcripciones de audio, vídeo, registros escritos de todo tipo, fotografías o películas y artefactos" (Pérez, 2012; Hernández, 2014).

El modelo investigativo trabajado es la investigación acción, que es una metodología de investigación orientada a la práctica educativa cuyo propósito general es mejorar las prácticas educativas. Sus características principales 
son la transformación y mejora de una realidad educativa (Cerda, 1997).

La unidad de análisis elegida estuvo conformada por los estudiantes de la Institución Educativa Distrital (IED) Rural de Tasajera sede Santiago Montaño.

En cuanto a instrumentos y procedimientos, se utilizó el método biográfico para la recolección de los datos (Bisquerra, 2016; Pujadas, 2002. A partir de las entrevistas realizadas a personas de tercera edad, los niños de la IED Santiago Montaño, realizaron un libro de historias de vida de la población de Tasajera en la cual se recopiló información relacionada con la tradición y cultura de este municipio.

\section{Resultados}

A partir de las entrevistas realizadas a personas de tercera edad, los estudiantes construyeron un libro de "Historias de Vida de la Población de Tasajera" en la cual se pueden encontrar historias como los siguientes extractos presentados aquí para ejemplificar:

"Dinda Mozo: Existen dos historias acerca de esta, la primera era que este pueblo era habitado por unos indígenas que cuyo cacique se llamaba tasajo y de hay el nombre de Tasajera..."

"Chadya Martínez: En Tasajera no había gas, no había recogedor de basura, las casas eran de tabla, los techos eran de teja, no había agua, no había luz, no había un colegio bachillerato, los pisos eran de tierra, las casas también eran de palma no eran pavimentadas"

"Yurianis Ferreira: Esta comunidad surgió debido a la construcción de la tasajera en el año 1947, por los Marichales, en este entonces existían 5 casas, hasta que después se fueron incrementando el caserío en el cursar del tiempo hasta formar la comunidad actual..."
"Johanis Acosta: Según estadísticas realizadas a lo largo y ancho de esta población se dice que Tasajera fue fundada en 1870 pero no se ha podido determinar que haya sido fundada por personas particulares sino que lo habitaron unas tribus, las cuales eran pescadores y venían de la Isla Salamanca, los cuales eran llamados los tasajos a estos se le debe el nombre de Tasajera...”

\section{Conclusiones}

Se puede evidenciar en los resultados obtenidos que es fundamental para fomentar la identidad cultural conocer las historias propias del corregimiento, apoyado en la comunidad, que en este caso fueron las personas de la tercera edad. Así los estudiantes lograran construir la historia de la población donde viven, y potencializar su sentido de pertenencia por la misma. La nueva generación necesita reconocer e identificarse como oriundos de Tasajera, lo cual implica involucrarse y reconocer las costumbres propias del corregimiento.

Para lo anteriormente planteado, sobre lo importante que es conocer lo orígenes, es fundamental hablar de ciertos factores que ayuden a llevar a cabo este tipo de procesos; entre ellos el entender la finalidad de adquirir conocimientos de este tipo. Al respecto, conviene revisar los aportes de Freire (1971), quien plantea que el objetivo de la educación debe ser que el niño adquiera la capacidad reflexiva de evaluar su realidad, descubriéndose como sujeto histórico inmerso en un sin número de discursos que difunden valores de dominación, y la intención es que formemos un niño con claridad de lo que le rodea, como sujeto libre y reflexivo, que genere cambios no solo personales sino sociales.

Teniendo en cuenta el objetivo principal de la educación, se puede incursionar comenzar desde las etapas iniciales 
del niño, como punto de partida para la implementación de una conciencia cultural, Al respecto, Pinto, M. y Misas, M. (2014),plantea que la etapa inicial, comprendida desde los cero hasta los seis años, es el momento propicio para la comprensión del mundo. Es en los primeros cinco años cuando se fomenta la creatividad, las bases para comprender el conocimiento científico y la interacción con el mundo, de una forma "despreocupada", que será fundamental en la carga experiencial que podrá adquirir el niño y utilizar en la construcción del conocimiento en etapas posteriores de escolarización.

En este sentido se pude afirmar, que la mejor manera de que el niño adquiera conciencia y sentido de pertenencia sobre su cultura, es implementando estrategias pedagógicas desde la etapa inicial para que, puedan crear aprendizajes significativos sobre las mismas.

En este sentido, en el desarrollo del niño, el papel del maestro tiene un rol muy importante en los primero grados, Franco, (2012). Con este planteamiento coinciden Talavera y Marín (2015) cuando reconocen la mediación didáctica como proceso clave para la resignificación de la labor docente, la concepción de ambientes de aprendizaje innovadores. El docente cumple el rol de guía, experto en el proceso de desarrollo de competencias en los estudiantes, promoviéndoles la construcción de conocimientos de manera significativa; cimienta las bases que favorezcan la comprensión lectora en estos niveles, promueven el uso de herramientas que les posibilita comprender su realidad, conocer la multiplicidad de significados, adoptar la apropiación de una de ellas y situándolos dentro de un contexto particular que le facilita participar en la sociedad, en igualdad de condiciones y aportar al desarrollo humano y social.
La afirmación anterior es el claro ejemplo, de que es fundamental trabajar todos los procesos de adquisición de cultura y sentido de pertenencia desde la etapa inicial, ya que los niños están más abiertos a nuevos conocimientos y sus capacidades cognitivas están en plena estructuración de nuevos enlaces en la adquisición de conocimiento.

Por otra parte es necesario, entender la relación de la niñez y la educación implica tener una aproximación compleja de este fenómeno social que no solo representa una institución (la escuela), sino que implica una serie de discursos que la conforman (por ejemplo, los discursos pedagógicos, políticos, psicológicos, éticos, los medios de comunicación, las redes y la familia; entre otros). No podemos hablar de la educación como un todo sin relación con sus partes: los educadores y los educandos, los profesores y los alumnos, los padres y la sociedad; pero tampoco podemos reducirla a sus partes, educación no son ni profesores, ni estudiantes, ni padres, ni instituciones, ni sociedad (Cruz, 2015).

La investigación es fundamental en procesos de búsqueda, construcción, adquisición y valoración del conocimiento. Estas son capacidades que progresivamente la escuela debe promover y desarrollar.

Una de las estrategias investigativas más exitosas son los semilleros, ellos son el claro ejemplo de las necesidades que tiene gran parte de la juventud por investigar y apropiarse de conocimientos. Por eso en su investigación Santacoloma, (2012) planeta: las instituciones de educación superior en Colombia tienen dentro de sus programas académicos o de investigación, proyectos de formación en los que se incluyen los semilleros de investigación. Estas dinámicas educativas pueden llegar a ser mucho más que una simple estrategia de formación y de 
desarrollo de la competencia investigativa, todo depende de cómo se trabaje, dirija y oriente a los semilleros de investigación.

La definición más acertada sobre los semilleros de investigación es la siguiente: El Departamento Administrativo de Ciencia, Tecnología e Innovación, COLCIENCIAS, (2009) recomienda en su condición de ente rector de la ciencia y la tecnología en Colombia, desarrollar estrategias pedagógicas extracurriculares que tienen como finalidad fomentar la cultura investigativa en estudiantes utilizando la investigación formativa y el trabajo en red. Teniendo certeza de que la investigación es fundamental en cualquier proceso, las problemáticas que se presenten, serán favorables, en el sentido que pueden transformarse en nuevos conocimientos, con las distintas estrategias investigativas, como aquellas anteriormente mencionadas.

Por último, es importante citar un ejemplo sobre esto dado en la investigación de Santacoloma, (2012):

Es necesario lograr que los niños y niñas del país presenten interés por la investigación o que los y las jóvenes se apropien del papel de dirigencia del país en otros frentes que no necesariamente sean los políticos, es un reto para el cual se requiere implementar una dinámica de interacción de muchos factores, para que se llegue a este propósito (2012).

Lograr que asesores, maestros y maestras, niños, niñas y jóvenes en general, se concentren en una entrelazada estrategia de formación en la investigación, para utilizarla como estrategia pedagógica o para cultivar el espíritu científico de la siguiente generación y de esta manera crear una cultura de investigación, ciencia y tecnología, es un aporte fundamental para el desarrollo del país, es casi un postulado de construcción de cultura y desarrollo sostenible y eficaz para Colombia (Colciencias, 2006).

\section{Referencias}

Bisquerra, R. (2016). Metodología de la investigación educativa. Madrid: Arco/Libros.

Cerda, H. (1997). La investigación total. Bogotá, D.C.: Cooperativa Editorial Magisterio.

Geertz, C. (2006). La interpretación de las culturas. Barcelona: Gedisa.

Giménez, G. (2012). La cultura como identidad y la identidad como cultura. Bogotá, D.C.: Instituto de Investigaciones Sociales de la UNAM. Recuperado de https://perio.unlp.edu. ar/teorias2/textos/articulos/gimenez. pdf

Cruz, M. (2015). La niñez en la escuela: Una historia de poder, control y desarrollo. Cultura Educación y Sociedad 6(1), 127-139.

De la Concepción, A. (2015). Concepciones sobre participación de niñas, niños y adolescentes: Su importancia en la construcción de la convivencia escolar. Cultura Educación y Sociedad, 6(2). Recuperado de https://revistascientificas.cuc.edu.co/culturaeducacionysociedad/article/view/840

Franco, M. (2012). Estrategias de enseñanza para la promoción de la comprensión lectora desde el aprendizaje significativo. Cultura, Educación y Sociedad, 3(1), 175-186. Recuperado de https://revistascientificas.cuc.edu. co/culturaeducacionysociedad/article/ view/963/pdf_183

Hernández, S. (2014). El modelo constructivista con las nuevas tecnologías: aplicado en el proceso de aprendizaje- Educrea. Educrea. Recuperado de https://educrea.cl/el-modelo-constructivista-con-las-nuevastecnologias-aplicado-en-el-procesode-aprendizaje/ 
Mejía, C. y Grisales, J. (s.f.). El saber pedagógico y el saber de maestros. En, 4 Congreso pedagógico. Universidad Católica de Manizales - Escuela Normal Superior Claudia Munera, Manizales. Recuperado de http://www.ucm. edu.co/wp-content/uploads/docs/ COMPILACION_CONGRESO.pdf

Mejía, M. y Manjarrés, M. (2011). La investigación como estrategia pedagógica una apuesta por construir pedagogías críticas en el siglo XXI. Praxis \& Saber, 2(4), 127. http://dx.doi. org/10.19053/22160159.1127

Molano, O. (2007). Identidad cultural un concepto que evoluciona. Universidad externado de Colombia. Revista Opera, 7(7), 69-84.

Morante, P. (2012). Promoviendo la identidad cultural desde el jardín de infantes. Redem.org. Recuperado de http://www.redem.org/boletin/boletin150312b.html

Orozco, M. (2015). Métodos, formas, procedimientos y sistemas de enseñanza en una concepción de la pedagogía como arte según José M. Zamora. Aula, 21(0), $165 . \quad$ http://dx.doi. org/10.14201/aula201521165176

Plan Maestro de las Culturas.(s/f). Fisal. org. Retrieved from Página 33 - Provincia de San Luis. Argentina. http:// www.fisal.org/Plan_Maestro_Cultura/files/assets/basic-html/page 33 . html

Pérez Serrano, G. (2012). Investigación cualitativa. Retos e interrogantes. II técnicas y análisis de datos. Madrid: la Muralla S.A.

Pinto, M. y Misas, M. (2014). La educación inicial y la educación preescolar: Perspectivas de desarrollo en Colombia y su importancia en la configuración del mundo de los niños. Cultura Educación y Sociedad, 5(1), 119-140.
Pujadas, J. (2002). El método biográfico. Madrid: Centro de Estudios Políticos y Constitucionales.

República de Colombia. Congreso de la República. COLCIENCIAS. (23 de enero de 2009). Por la cual se modifica la ley 29 de 1990, se transforma a colciencias en departamento administrativo, se fortalece el sistema nacional de ciencia, tecnología e innovac:ón en colombia y se dictan otras disposiciones. [Ley 1286]. Diario Oficial 47.241. Departamento Administrativo de Ciencia, Tecnología e Innovación. Colciencias, Congreso de Colombia. Disponible en http://www.colciencias.gov. co/sites/default/files/upload/reglamentacion/ley_1286_2009.pdf

Rodriguez, O. (2015). La investigación acción y la construcción de la identidad histórico cultural. A la otra orilla. Recuperado de https://alaotraorilla. wordpress.com/2015/05/06/hola-mundo//

Samper, J. y Maussa, E. (2014). Desarrollo moral y competencias ciudadanas en la juventud universitaria. Jurídicas CUC, 10 (1), 43-60. Recuperado de https://revistascientificas.cuc.edu.co/ juridicascuc/article/view/459/pdf_42

Santacoloma, A. (2012). Los semilleros de investigación como estrategia de formación integral para ciudadanos del tercer milenio. Cultura, Educación y Sociedad. 3(1), 13 22. Recuperado de https://revistascientificas.cuc. edu.co/culturaeducacionysociedad/article/view/963/pdf_183

Talavera, R. y Marín, F. (2015). Recursos tecnológicos e integración de las ciencias como herramienta didáctica. Revista de Ciencias Sociales (Ve) [en linea], XXI. Disponible en http://www. r e d a l y c . o r g / a r t i c u lo. oa?id=28041012011> 
Villalba, A. (2012). Dos paradigmas contrapuestos en la evaluación educativa, dos formas diferentes de concebir al alumno. Aula Universitaria, 1(14). http://dx.doi.org/10A 